\title{
Optimization of PID Tuning Using Genetic Algorithm
}

\author{
Tengku Ahmad Faris Ku Yusoff ${ }^{1}$, Mohd Farid Atan ${ }^{2}$, Nazeri Abdul Rahman ${ }^{3}$, Shanti \\ Faridah Salleh ${ }^{4}$ and Noraziah Abdul Wahab ${ }^{5}$ \\ 1,2,3,4,5 Department of Chemical Engineering and Energy Sustainability, Faculty of \\ Engineering, Universiti Malaysia Sarawak, Kuching, Sarawak, Malaysia. \\ ${ }^{1}$ Email: tgfaris@live.com, ${ }^{2}$ Email: amfarid@unimas.my, \\ ${ }^{3}$ Email: arnazeri@unimas.my, Email:sshanti@unimas.my, \\ ${ }^{5}$ Email:anoraziah@unimas.my
}

\begin{abstract}
Controller tuning is one of the important aspect in industry. With a good tuning method, it can ensure the quality of the process and product produce. Apart from that, it can protect the environment and help the company to reduce the cost. Genetic algorithm is one of the tuning method that increase usage and awareness in industry. Thus, the objective of this research is to compare the performance of the conventional tuning method with the performance of tuning method by using genetic algorithm can be seen. Optimization was done on stripping section of distillation column by using genetic algorithm with population size of 20, 40, 60 and 80 and comparing the result with previous optimization using Ziegler-Nichols method. The result obtain showed large improvement in the process response especially on rise time from $1.33 \mathrm{~s}$ to 1.31 s and settling time from 4.56 to 4.46. Finally, population size of 40 deliver the fastest rise time and settling time.
\end{abstract}

Keywords: tuning method, genetic algorithm

\section{Introduction}

Proportional, Integral and Derivative (PID) controller is a common form of feedback (Astrom, 2002). It has been widely used in process industries due to their simple structure which can be easily understood and implemented in practice (Awouda, 2010). A good PID controller can ensure the process to work efficiently and help the industries to reduce the environmental issues while maintaining the quality of the product that being process. For PID controller to work properly, it has to be tuned. Genetic algorithm is a modern optimization technique that being studied by most researchers in searching the optimal PID parameters. It is inspired by Darwin's theory of evolution which states that the survival of an organism is affected by rule "the strongest species that survives" (Hermawento, 2013). Genetic algorithm can provide solutions for highly complex search space and perform well approximately solution for all types of problems because they do not make any assumption about the underlying fitness landscape (Zvirgzdina \& Tolujevs, 2013).

The objective of this project is to understand and investigate the efficiency of genetic algorithm in PID tuning. In PID tuning, it is important to obtain the best solution so that the

Manuscript History:

Received 4 August, 2015, Revised 9 September, 2015, Accepted 10 September, 2015, Published 30 September, 2015

e-ISSN 2289-7771

Copyright $\odot 2015$ JASPE

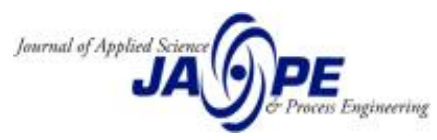


controller will have the fastest and stable response time. Lastly, this project contribute on the improvement of control parameters for distillation column

\section{Methodology}

The general form of PID controller is given as

$$
G_{c}=K\left(1+\frac{1}{\tau_{i} S}+s \tau_{d}\right)
$$

To determine the controller, the transfer function of the system must be determine and is use to generate a better parameter for the proportional time, integral time and derivative time. This project will optimize stripping section in distillation column with the following transfer function (Samah, 2014).

$$
(s)=\frac{-0.3654 s+0.657}{s^{2}+1.642 s+1.982}
$$

The basic process of genetic algorithm that being used in MATLAB can be outlined into 6 basic steps as follow:

Step 1: [Start] Generate random population of chromosomes which represent the number of solutions that is suitable for the problem.

Step 2: [Fitness] Evaluate the fitness of each chromosome in the population.

Step 3: [New population] create a new population by repeating following steps until the new population is complete:

a) [Selection] Select two parent chromosomes from a population according to their fitness. Better the fitness, the bigger chance to be selected to be the parent.

b) [Crossover] With a crossover probability rate of 4 , crossover the parents to form new offspring that is children. If no crossover was performed, offspring is the exact copy of parents.

c) [Mutation] With a mutation probability of 8 , mutate new offspring at each locus.

d) [Reproduction] Place new offspring in the new population.

Step 4: [Replace] Use new generated population for a further run of the algorithm.

Step 5: [Test] If the end condition is satisfied, stop, and return the best solution in current population.

Step 6: [Loop] Go to step 2. The generation is repeat for 100 times.

The step in genetic algorithm had been summarized as shown in Figure 1. The genetic algorithm was initialized with several number of population started with 20 . It then initialized with population size of 40,60 , and 80 . The response of result produced will be analyzed in term of overshoot, rise time and settling time. All the responses from GA will be compared with the responses obtain by using Ziegler Nichols method. 


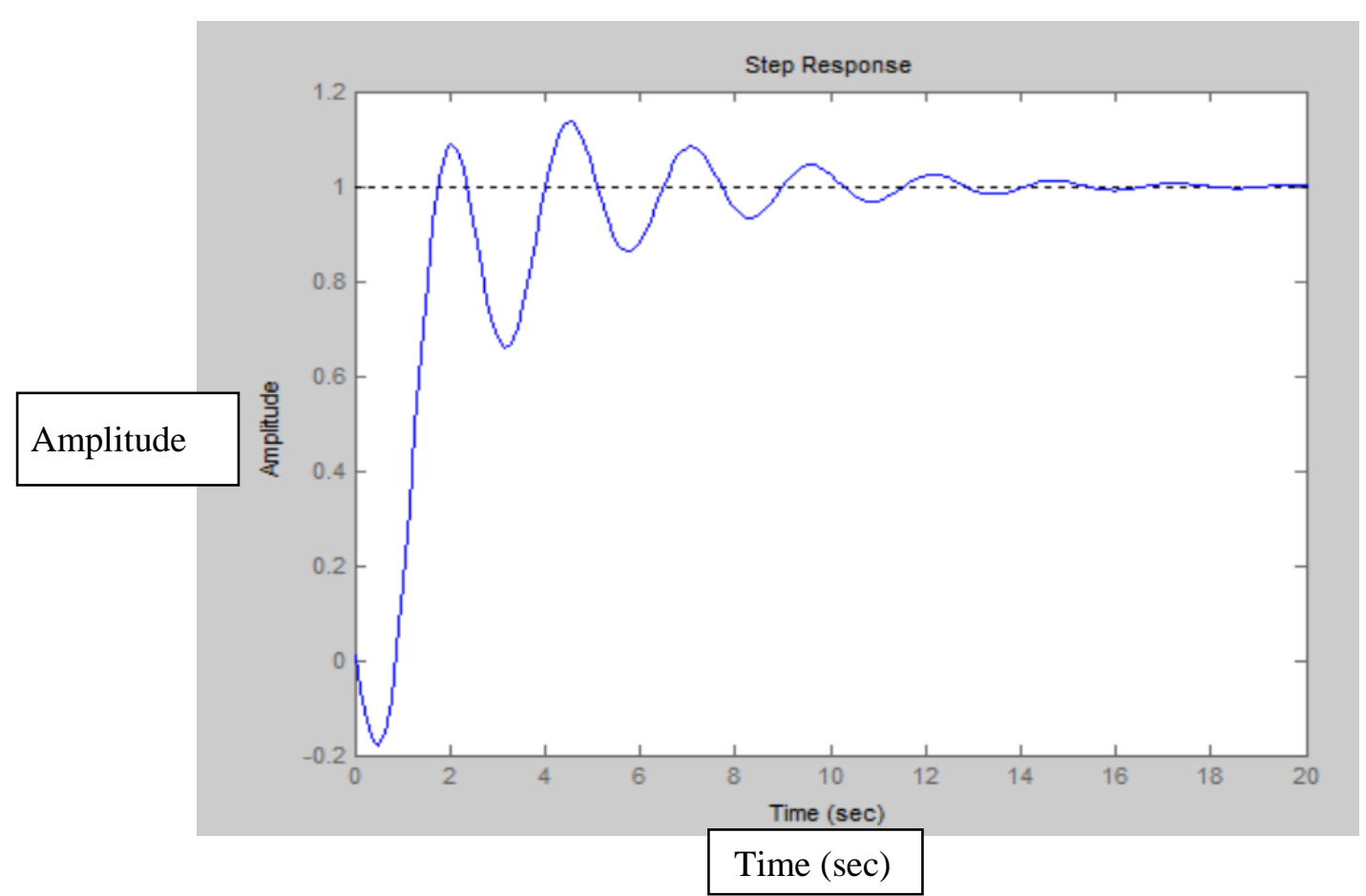

Figure 1: Step Response by Using Ziegler Nichols (Samah , 2014)

\section{Results and Discussion}

From Figure 2, the responses of the system has fast rise time which is 0.66 seconds. Rise time is defined as the time required for the response to raised from $10 \%$ to $90 \%$ of its final value. However, the peak amplitude is 1.11 and produce oscillation that increase the time for the system to reach steady state. The overshoot of the response is $13.6 \%$. The maximum overshoot is increase as the damping ratio increase. Based on the result showed, the overshoot produce does not fall in the required range and the robustness of the response showed uncertainty which result in the increase of time for the system to achieve steady state. The result will be compared against the controller that been optimize using GA. 


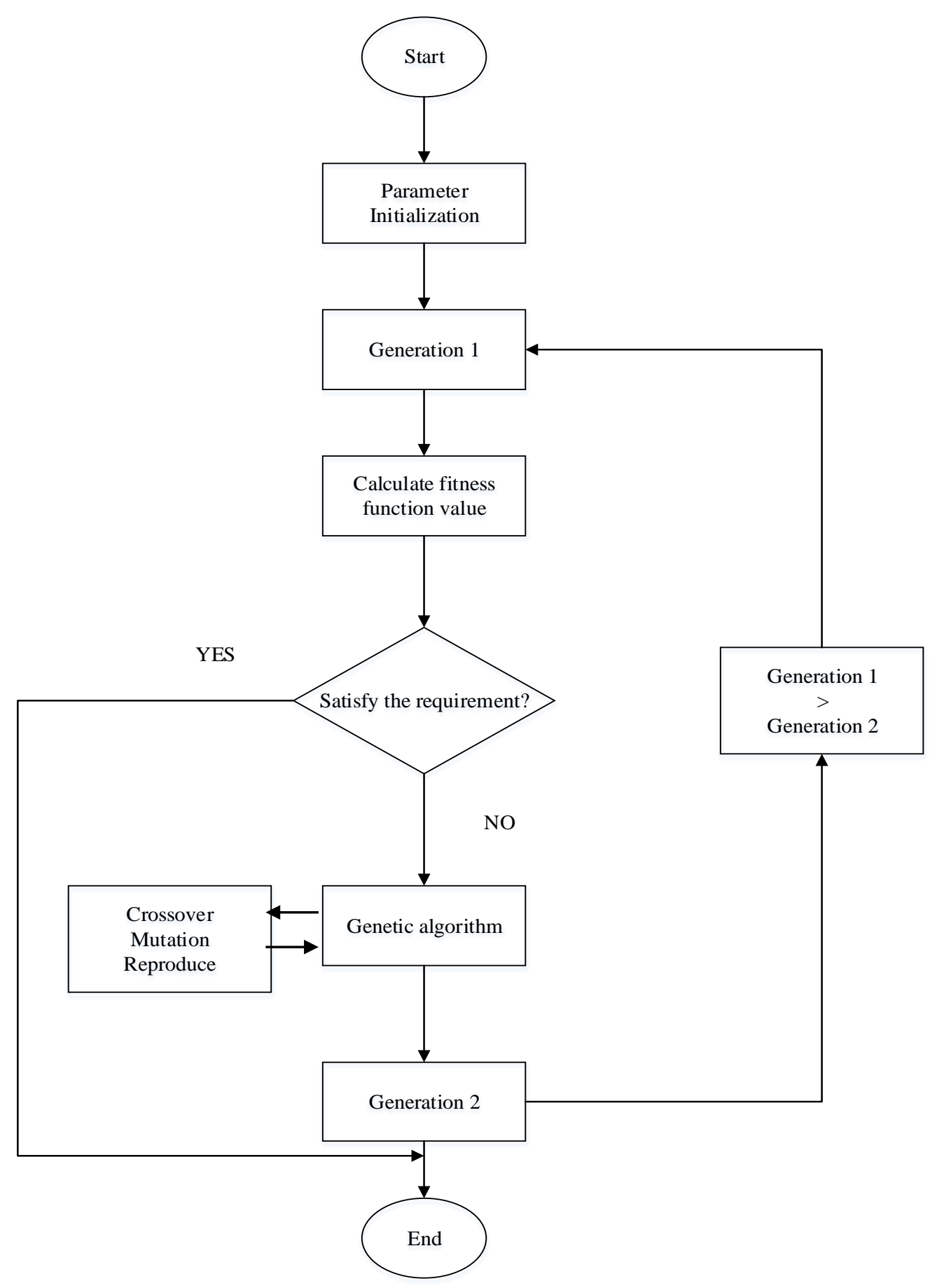

Figure 2: Simulation flow chart for auto tuning GA-PID controller. 


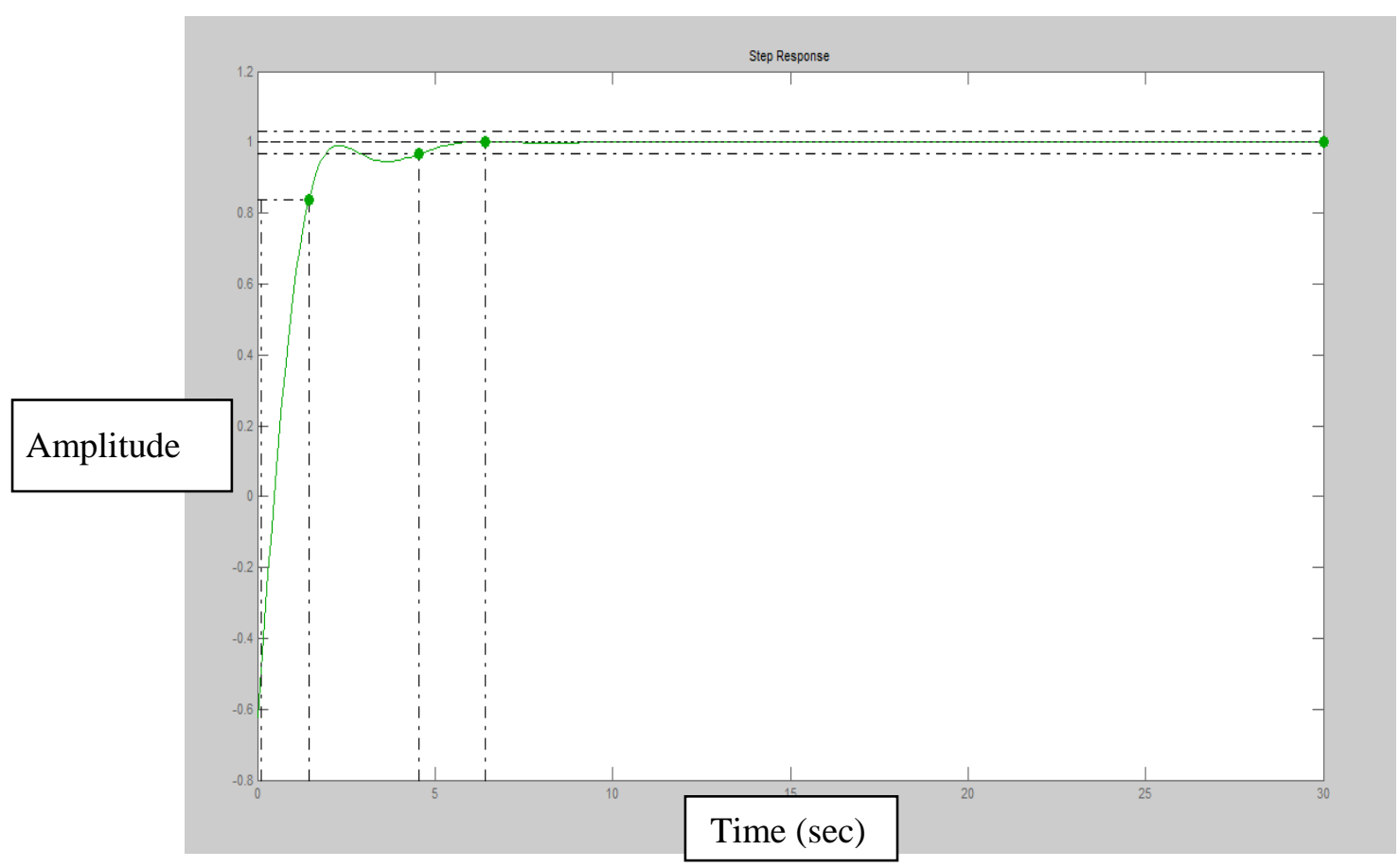

Figure 3: Step Response with Population Size of 20.

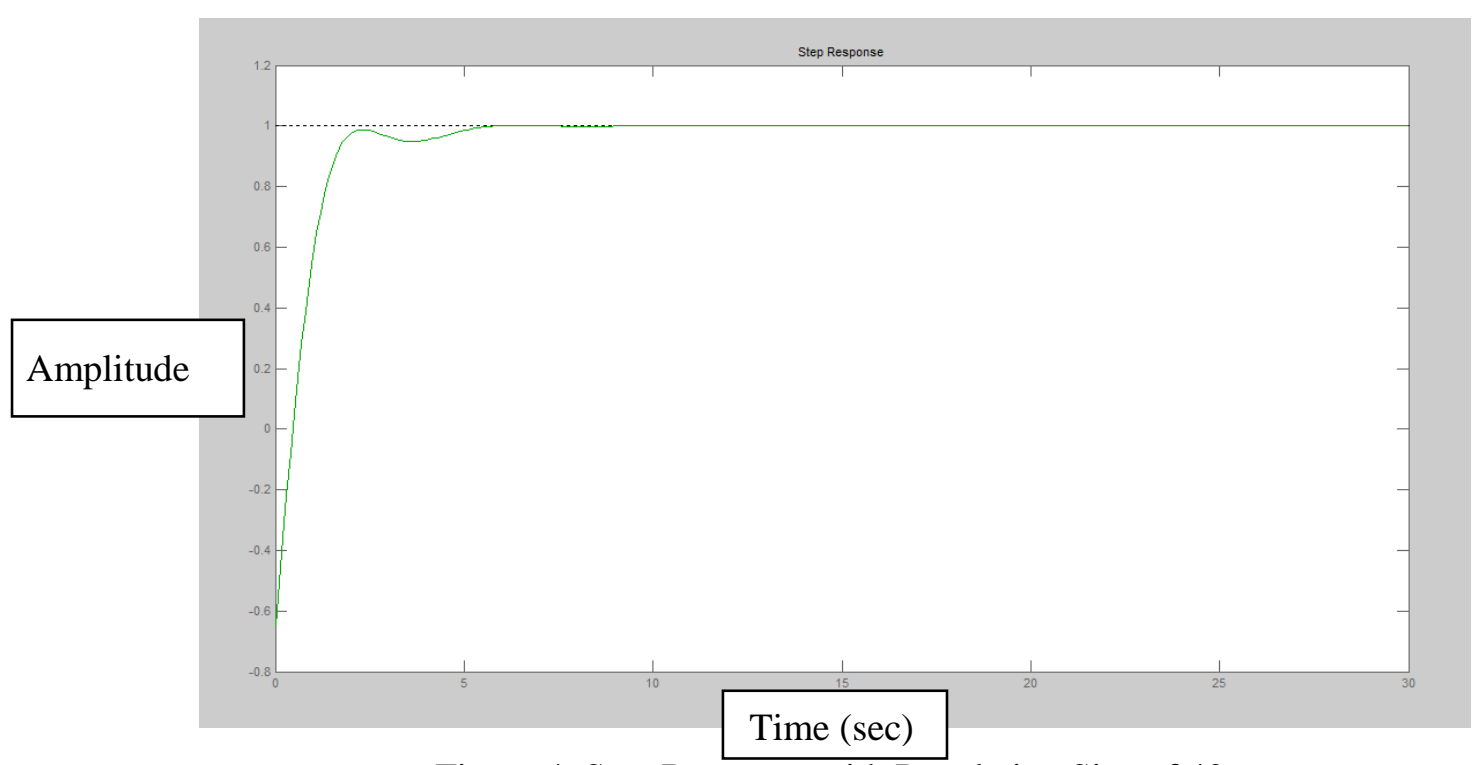

Figure 4: Step Response with Population Size of 40. 


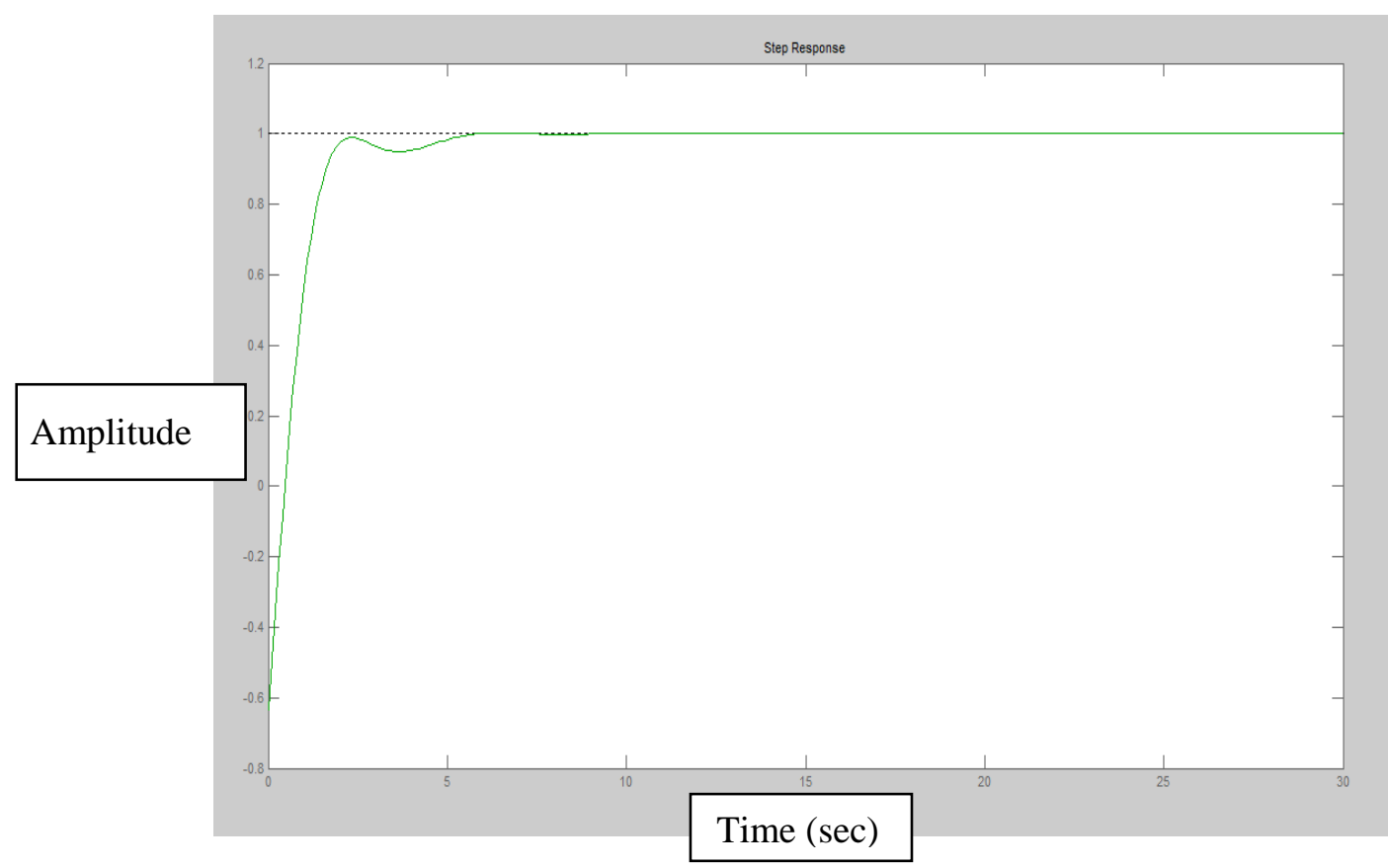

Figure 5: Step Response with Population Size of 60.

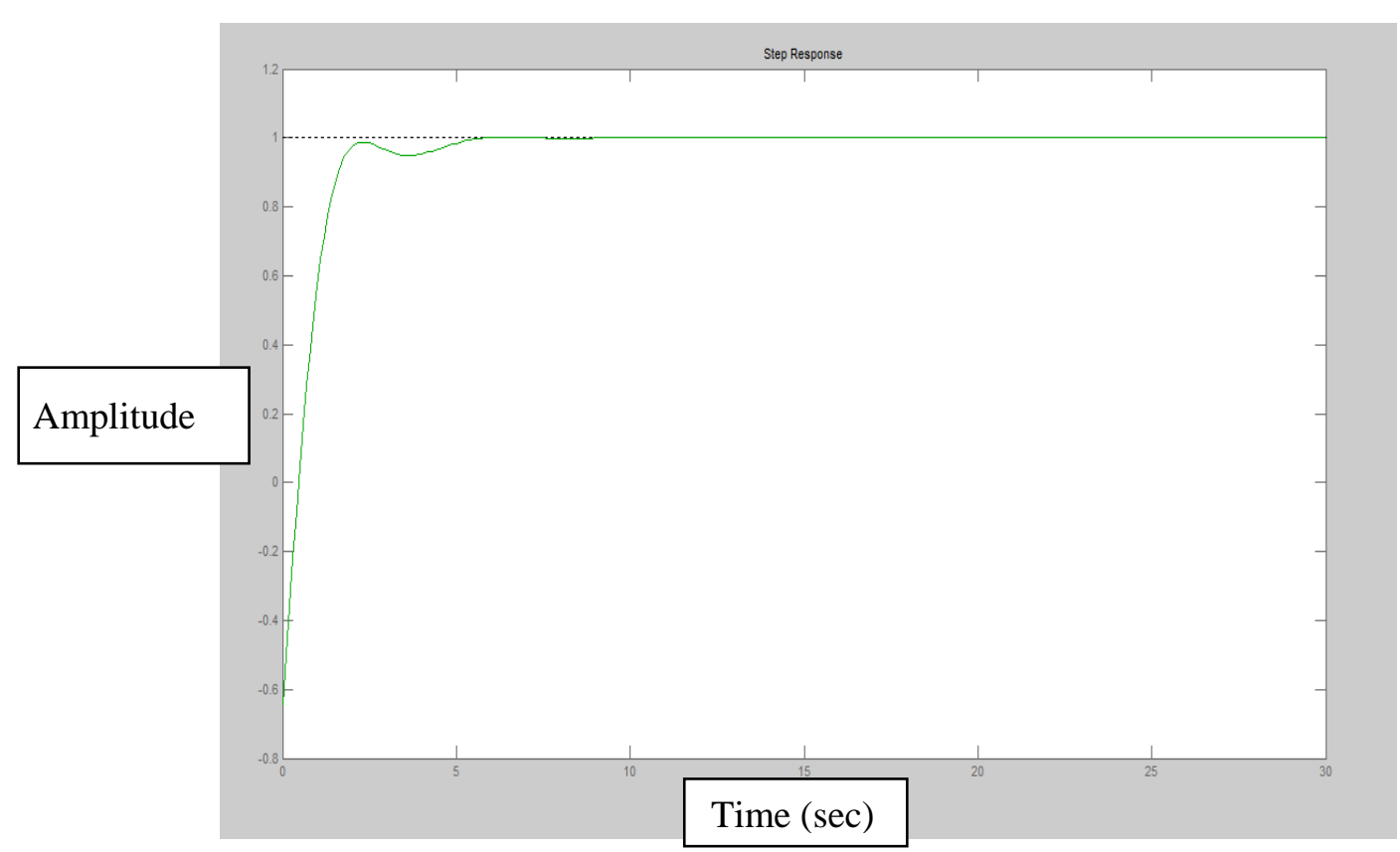

Figure 6: Step Response with Population Size of 80. 
Table 1: Gain Value Obtain by using GA

\begin{tabular}{|c|c|c|c|}
\hline Population Size & $\begin{array}{c}\text { Kp (Propotional } \\
\text { Gain) }\end{array}$ & Ki (Integral Gain) & $\begin{array}{c}\text { Kd (Derivative } \\
\text { Gain) }\end{array}$ \\
\hline \hline 20 & 2.2213 & 2.3834 & 1.0499 \\
\hline 40 & 2.2331 & 2.4106 & 1.0764 \\
\hline 60 & 2.2152 & 2.3973 & 1.0619 \\
\hline 80 & 2.2324 & 2.4070 & 1.0736 \\
\hline
\end{tabular}

Table 2: Details of System Response by Optimizing using GA

\begin{tabular}{|c|c|c|c|}
\hline No. of Population & $\begin{array}{c}\text { Rise Time } \\
\text { (seconds) }\end{array}$ & $\begin{array}{c}\text { Maximum } \\
\text { Overshoot } \\
\text { (amplitude/percent) }\end{array}$ & $\begin{array}{c}\text { Settling Time } \\
\text { (seconds) }\end{array}$ \\
\hline \hline 20 & 1.32 & $1 / 0.197$ & 4.56 \\
\hline 40 & 1.31 & $1 / 0.183$ & 4.46 \\
\hline 60 & 1.33 & $1 / 0.195$ & 4.5 \\
\hline 80 & 1.31 & $1 / 0.183$ & 4.47 \\
\hline
\end{tabular}

Based on the Figure 4 to Figure 6, the step response showed a faster response compare to using the conventional optimization method. The result from the graph obtain based on the gain value that are tabulated in Table 1 which are different and more consistent compare to the data from Ziegler-Nichols method. The data from Table 2 showed that by optimizing using GA, the best response can be obtain even at population size of 20. It can be seen that there is no significant difference in the response obtain at different population size. Apart from that the overall system stability also increase compare to using Ziegler-Nichols method. Although the rise time is longer than Ziegler-Nichols method, the time for the system to reach steady state is faster.

The table showed that as the population size increase from 20 to 40, the rise time, and settling time become faster and it reduce the maximum overshoot. However, when the population size is increase to 60 , the response of the system is reduce and increase again when the population size is further increase to 80 . This is due to the properties of the GA itself that can cause a poor premature convergence and loss of best solution found.

\section{Conclusions and Recommendations}

This project focused on improving the PID tuning by using GA which adapted from Darwin's theory of evolution. The results generated from the method were compared with the conventional tuning method which are the Ziegler-Nichols tuning method. Based on the comparison it been proved that optimization by using GA can improve the performance of controller compare to the Ziegler-Nichols method. The result showed that by tuning the PID controller using GA with population size of 60 is the best as it increase the response time, 
settling time and reduce the overshoot of the system response. By increasing the performance of the control system, the quality of the production can be maintain.

Throughout the project, it is found that to perform GA for optimization of PID tuning, there are a lot of works need to be done such as trial and error. Although the problem could be solve by optimizing using classical method, but it will result to time consuming and in industrial sector, it will cost them money due to need of another tuning method need to be done. Thus, by having a proper and faster method to predict the suitable parameter for the GA, the usage of GA in optimization can be improve. Apart from that, the result produced by optimizing using GA can be improved by introduced suitable constraint. There are several constraint that can be used such as penalty function, search of feasible solution, preserving feasibility of solutions and hybrid method.

\section{Acknowledgement}

The author wishes to thanks to all individuals who contributed to the production of this thesis for their continuous moral support, advices, and guidance. An appreciation is also extended to Mr Mohd Farid bin Atan for his encouragement, guidance, supports and also advices toward the completion of this study. A sincere appreciation goes to Final Year Project Coordinator, Mdm Noraziah Abdul Wahab, for her guidance. Last but not least, the author would like to thank her parents, $\mathrm{Ku}$ Yusoff bin Tuan $\mathrm{Pa}$ and Zamilah binti Zakaria and friends for their supports, helps and encouragements throughout of the course of his study.

\section{References}

Arturo, Y. J. C., Rene, D. J. R. T., Luis, M. V., \& Roque, A. O. R. (2013). PID- Controller Tuning Optimization with Genetic Algorithms in Servo Systems. doi:10.5772/56697

Astrom, K. J. (2002). PID Control. In Control System Design (pp. 216-251). Bansal, H. O., Sharma, R., \& Shreeraman, P. R. (2012). PID Controller Tuning Techniques: A Review, 2(October), (pp. 168176).

A Awouda, A Eldin, R Mamat (2010). New PID tuning rule using ITAE criteria. International Journal of Engineering 3 (6), 597-608

B. Anandaraju, M., Puttaswamy, P. S., \& Singh Rajpurohit, J. (2011). Genetic Algorithm: An approach to Velocity Control of an Electric DC Motor. International Journal of Computer Applications, 26(1), 37-43. doi:10.5120/3066-4191

Beasley, D., \& Bull, D. R. (1993). An Overview of Genetic Algorithms: Part 1, Fundamentals 1 Introduction 2 Basic Principles, 1-16.

Chipperfield, A., Fleming, P., Pohlheim, H., \& Fonseca, C. (n.d.). Genetic Algorithm Toolbox.

Chopra, V., Singla, S. K., \& Dewan, L. (2014). Comparative Analysis of Tuning a PID Controller using Intelligent Methods, 11(8), 235-249

Coa, Y. J., \& Wu, Q. H. (1999). TEACHING GENETIC ALGORITHM USING MATLAB, 36, (pp. 139-153).

Engineering, C. (2011). Tuning of Pid Controller By Bioinspired Techniques Tuning of Pid Controller By Bioinspired Techniques. Technology.

Hermawanto, D. (2013). Genetic algorithm for solving simple mathematical equality problem. arXiv Preprint arXiv:1308.4675. Retrieved from http://arxiv.org/abs/1308.4675

Hussain, K. M., Allwyn, R., \& Kumar, S. M. G. (2014). Comparison of PID Controller Tuning Methods with Genetic Algorithm for FOPTD System Rajendran, 4(2), 308-314.

Ibrahim, S. M. (2005). THE PID CONTROLLER DESIGN USING GENETIC ALGORITHM.

Ii, A. (2004). MATLAB Code. N/a, 211-232. doi:10.1201/9781420035636.axd

Jones, G. (n.d.). Genetic and Evolutionary Algorithms

Kanthalakshimi, S., \& Manikandan, V. (2010). Genetic Algorithm Based Self Tuning Regulator, 2(12), (pp. 7719-7728).

Katal, N., \& Singh, S. K. (2012). Optimization of PID Controller for Quarter-Car Suspension System using Genetic Algorithm, 1(7), 30-32. 
Kaushal, J. (2012). Controller Tuning for Speed Control of DC Motor Drives.

Khatri, P., \& Dalal, M. (2013). Implementation of Genetic Algorithm to Temperature Control System, 3(6), 1868-1871.

Konak, a, Coit, D. W., \& Smith, a E. (2006). Multi-objective optimization using genetic algorithms: A tutorial. Reliability Engineering and System Safety, 91(9), 992-1007. doi:10.1016/j.ress.2005.11.018

Mantri, G., \& Kulkarni, N. R. (2013). DESIGN AND OPTIMIZATION OF PID CONTROLLER USING GENETIC ALGORITHM, (1), (pp. 926-930).

Melanie, M. (1996). An Introduction to Genetic Algorithms (5th ed.). London, England: The MIT Press.

Mirazal, A., Yoshii, S., \& Furukawa, M. (n.d.). PID Parameters Optimization by Using Genetic Algorithm.

Ohri, J., Kumar, N., \& Chinda, M. (n.d.). An Improved Genetic Algorithm for PID Parameter Tuning.

Saad, M. S., Jamaluddin, H., \& Darus, I. Z. M. (2012). Implementation of PID Controller Tuning Using Differential Evolution and Genetic Algorithm. International Journal of Innovative Computing, Information and Control, 8(11), (pp. 7761-7779).

Science, I. (2012). PID Parameters Optimization by Using Genetic Algorithm Andri Mirzal, Shinichiro Yoshii, Masashi Furukawa.

Sekaj, I., \& Technology, I. (n.d.). Genetic Algorithms for Control System Design Applications, 31-37.

Seyedkazemi, M. (2008). Designing Optimal PID controller with Genetic Algorithm In view of controller location in the plant, 160-164.

Tolujevs, J. (2013). EVOLUTIONARY OPTIMIZATION OF A FLOW LINE USED ExtendSim BUILT-IN OPTIMIZER, (October), 155-162.

Saad, M. S., Jamaluddin, H., \& Darus, I. Z. M. (2012). PID Controller Tuning Using Evolutionary Algorithms, 7(4), (pp. 139-149).

Samah Sir Elkhtem., Gasmelseed, G. A., Karama, B. A. (2014). Transfer Function Identification and Tuning of Crude Distillation Unit Controller at Khartoum Refinery- Sudan, Journal of Applied and Industrial Sciences.

Samanta, S. (2014). Genetic Algorithm : An Approach for Optimization (Using MATLAB ), 3(3), 261267.

Srinivas, P., Lakshmi, K. V., \& Kumar, V. N. (2013). Design of GA based PID Controller for three tank system with various Performance Indices, (5), (pp. 206-209).

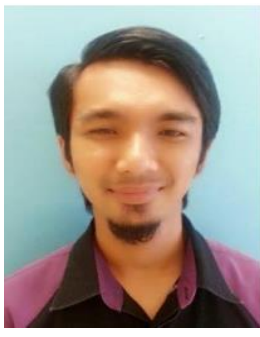

\section{Authors}

\section{Tengku Ahmad Faris Ku Yusoff}

Tengku Ahmad Faris Ku Yusoff was a student in Department of Chemical Engineering and Energy Sustainability, Faculty of Engineering, Universiti Malaysia Sarawak (UNIMAS). He received his B.Eng (Hons) in Chemical Engineering from UNIMAS.

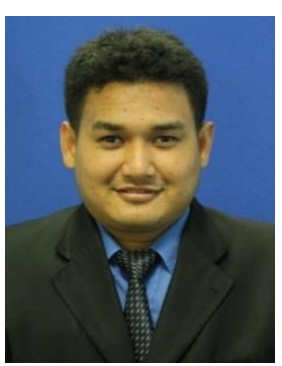

\section{Mohd Farid Atan}

Mohd Farid Atan is a Lecturer at Department of Chemical Engineering and Energy Sustainability, Faculty of Engineering, Universiti Malaysia Sarawak (UNIMAS). He received his M.Eng Diploma in Chemistry and Process Engineering from ESCPE Lyon, France. His areas of specialization are chemical processing and wastewater treatment. 


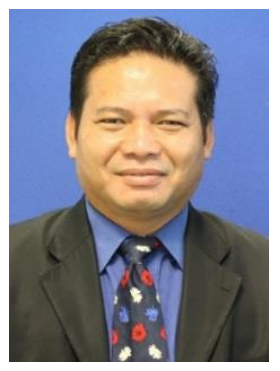

\section{Nazeri Abdul Rahman}

Nazeri Abdul Rahman is a Lecturer at Department of Chemical Engineering and Energy Sustainability, Faculty of Engineering, Universiti Malaysia Sarawak (UNIMAS). He received his M.Eng in Thermal Power and Fluid Engineering from UMIST. His areas of specialization are renewable energy.

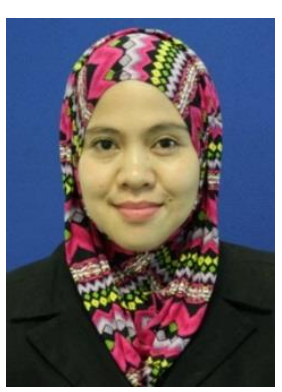

\section{Shanti Faridah Salleh}

Shanti Faridah Salleh is a Senior Lecturer at Department of Chemical Engineering and Energy Sustainability, Faculty of Engineering, Universiti Malaysia Sarawak (UNIMAS). She received her $\mathrm{PhD}$ in Chemical Engineering from Universiti Putra Malaysia (UPM). Her areas of specialization are renewable energy.

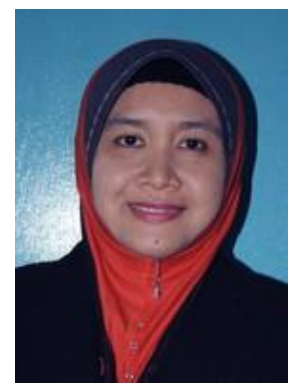

\section{Noraziah Abdul Wahab}

Noraziah Abdul Wahab is a Lecturer at Department of Chemical Engineering and Energy Sustainability, Faculty of Engineering, Universiti Malaysia Sarawak (UNIMAS). She received her Master in Chemical Engineering from Universiti Malaysia Sarawak (UNIMAS). Her areas of specialization are wastewater treatment. 